\title{
Nutritional status of schoolchildren in rural Iran
}

\author{
Zahra Sarraf ${ }^{1}$, Dena Goldberg ${ }^{2}$, Mohammad Shahbazi $^{3}{ }^{*}$, Kristen Arbuckle $^{4}$ and Moosa Salehi ${ }^{1}$ \\ ${ }^{1}$ Shiraz, University of Medical Sciences, Shiraz, Iran \\ ${ }^{2}$ University of Wyoming, Laramie, WY, USA \\ ${ }^{3}$ Jackson State University, School of Public Health, Jackson, MS, USA \\ ${ }^{4}$ Tulane School of Public Health and Tropical Medicine, New Orleans, LA, USA
}

(Received 15 March 2004 - Revised 28 February 2005 - Accepted 22 March 2005)

\begin{abstract}
The present study compared the nutritional status of schoolchildren from recently settled, ethnic minority tribespeople with those from a Persian village in southern Iran. Height and weight were measured and blood was collected from school children at three time points over 1.5 years. Supplemental Fe was provided to children with low $\mathrm{Hb}$ after the first screening. Twenty-one per cent of the children were wasted, $57 \%$ were stunted and $23 \%$ were anaemic. No statistically significant difference in the prevalence of wasting, stunting and anaemia was found between gender or ethnic groups. Children over the age of 12 years had a higher prevalence of wasting than children aged below 12 years. In a sub-sample of forty-one children the average BMI-for-age decreased. Fe supplementation increased $\mathrm{Hb}$ levels to normal in most children, but did not increase Fe level in a few children. Dietary deficiency of micronutrients, especially $\mathrm{Zn}$ and $\mathrm{Fe}$, probably accounts for the high prevalence of stunting and anaemia in these children. Infection with Helicobacter pylori is another possible explanation for the Fe-deficiency anaemia. Further investigation is in progress to determine the cause(s) of the observed deficiencies.
\end{abstract}

Iran: Qashqa'i: Schoolchildren's health status

Iran is located in the Middle East, bordering the Gulf of Oman, the Persian Gulf and the Caspian Sea, between Iraq and Pakistan. It shares borders with Afghanistan, Armenia, Azerbaijan, Iraq, Pakistan, Turkey and Turkmenistan. Iran is divided into twentyeight provinces (Fig. 1). The population is young, with a median age of 22.9 years, and about $29 \%$ are under the age of 15 years (CIA, 2003).

Iran faces several public health challenges. The infant mortality rate is $44 \cdot 17$ per 1000 live births (CIA, 2003). Malnutrition is not uncommon especially in rural and southern Iran. According to a 1998 nationwide study of children $<5$ years of age, approximately $15 \%$ are moderately or severely stunted $(<-2 \mathrm{SD}$ weight-for-age) and about $5 \%$ moderately or severely wasted $(<-2$ SD weight-for-height; Ministry of Health and Medical Education, 1998). Substantial differences exist between rural and urban provinces. Twenty-two per cent of rural children aged $<5$ years are stunted compared with $11.0 \%$ of urban children. The highest rate of stunting is $38.1 \%$ in Sistan va Baluchestan in the south east and the lowest is $6.8 \%$ in Gilan in the north east. The difference in the prevalence of wasting between rural and urban areas is small, with $5.6 \%$ of urban and $4.6 \%$ of rural children meeting the criteria for wasting. However, the difference between provinces is large. The highest rate of wasting is $11.3 \%$ in Harmozgan in the south west and the lowest rate is $1.1 \%$ in Golestan in the north west (Ministry of Health and Medical Education, 1998).
The same study revealed that only $14 \%$ of children had their weight recorded regularly on their growth card, with $69 \%$ having two or fewer weights recorded (Ministry of Health and Medical Education, 1998). During the week preceding the interview, protein-rich foods (meat, eggs and legumes) were offered about twelve times, vegetables about twelve times, fruit about more than seventeen times and dairy products about fourteen times to toddlers aged 12-23 months. Given the marginal intake of Fe-rich foods, it is noteworthy that only $74 \%$ of children aged $6-23$ months were receiving Fe supplements on a regular basis.

Factors that contribute to the malnutrition are low socioeconomic status, low health and nutritional awareness, inadequate access to health services, availability of a limited variety of foods, food insecurity in rural areas, recurrent diarrhoea and respiratory infections (Ministry of Health and Medical Education, 1998).

On the other hand, Tehran and other urban areas are beginning to experience the onset of the diseases of development, such as obesity and CVD (Azizi et al. 2001a,b). A 2001 study of 10-19-year-olds in Tehran ( $n$ 421) found that $10.7 \%$ and $5.1 \%$ of boys were overweight and obese, respectively, while $18.4 \%$ and $2.8 \%$ of girls were overweight and obese (Azizi et al. $2001 a$ ). This Tehran lipid and glucose study also reported that $16 \%$ of children aged $3-19$ years ( $n$ 3148) had a total cholesterol level of $200 \mathrm{mg} / \mathrm{dl}$ or greater and $17 \%$ had LDL-cholesterol level of $170 \mathrm{mg} / \mathrm{dl}$ or greater (Azizi et al. 2001b). The American Academy of Pediatrics considers total cholesterol of $200 \mathrm{mg} / \mathrm{dl}$ or

\footnotetext{
Abbreviation: NHANES III, Third National Health and Nutrition Examination Survey.

* Corresponding author: Dr Mohammad Shahbazi, fax +1 601368 2081, email mohammad.shahbazi@jsums.edu

$\dagger$ Address for correspondence: 144 Apple Blossom Drive, Brandon, MS 39047 , USA.
} 


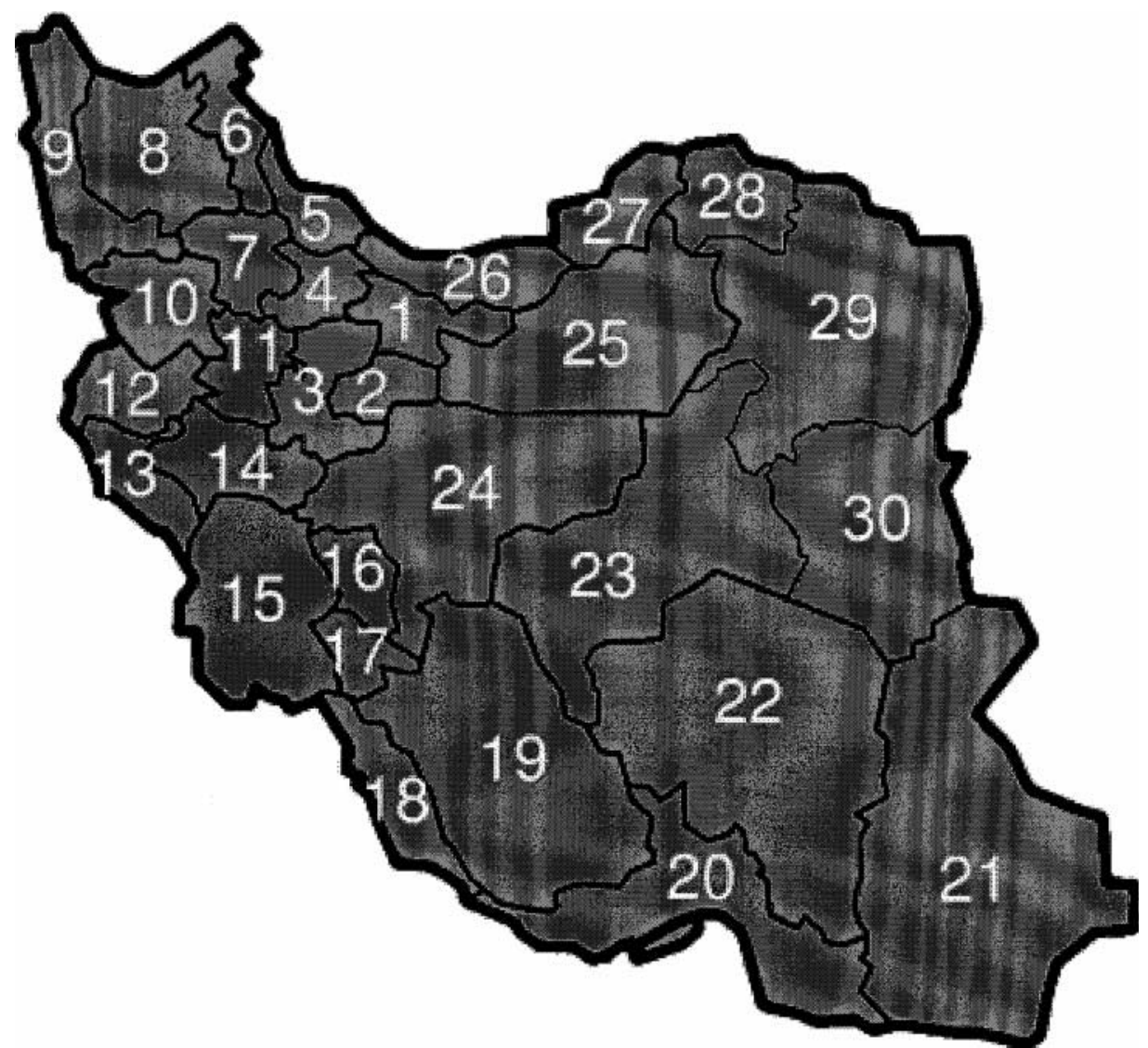

Fig. 1. Map of Iran showing the twenty-eight provinces. 1) Tehran; 2) Qom; 3) Markazi; 4) Qazvin; 5) Gilan; 6) Ardabil; 7) Zanjan; 8) East Azarbaijan; 9) West Azarbaijan; 10) Kurdistan; 11) Hamadan; 12) Kermanshah; 13) Ilam; 14) Lorestan; 15) Khuzestan; 16) Chahar Mahaal and bakhtiari; 17) Kohkiluyeh and Buyer Ahmad; 18) Busheher; 19) Fars; 20) Hormozgan; 21) Sistand and Baluchistan; 22) Kerman; 23) Yazd; 24) Esfahan; 25) Semnan; 26) Mazandaran; 27) Golestan; 28) North Khorasan; 29) Razavi Khorasan; 30) South Khorasam.

greater and LDL-cholesterol levels $130 \mathrm{mg} / \mathrm{dl}$ or greater high (American Academy of Pediatrics Committee on Nutrition, 1998).

Fe deficiency is another nutritional concern in Iran. A study of 583 children aged $<5$ years in Fars province reported a prevalence of Fe-deficiency anaemia of $18.7 \%$ (Kadivar et al. 2003). Another study of pregnant women at 16 weeks' gestation in southern Iran reported that $28.5 \%$ had low ferritin values and $16.7 \%$ had low $\mathrm{Hb}$ (Karimi et al. 2002). Fe-deficiency anaemia impacted negatively on performance in school examinations in a study of 800 school children in Saudi Arabia (Abalkhail \& Shawky, 2002). Fe deficiency is due to a combination of dietary factors: low $\mathrm{Fe}$ intake and high consumption of whole grains rich in phytates, and frequent consumption of tea, which inhibits absorption of Fe. Additionally, high birth rates, short pregnancy intervals and parasitic infections, which increase losses, contribute to anaemia (World Health Organization Regional Office for the Eastern Mediterranean, 2001; Dickey, 2002).

Little information is known regarding the nutritional status of school-aged children, especially among ethnic minority and 'hard-to-reach' populations such as the Qashqa'i tribespeople (Zohouri \& Rugg-Gunn, 2002). The Qashqa'i are a Turkishspeaking minority ethnic group of more than a half a million people residing in southern Iran. Some live a nomadic lifestyle and others have settled in small villages. They are considered a high-risk population in terms of their health status (Zohouri \& Rugg-Gunn, 2002). The infant mortality rate among the Qashqa'i was reported as 84.3 per 1000 live births (Keshavarz \& Sarraf,
1997), compared with the national level of $44 \cdot 17$ per 1000 live births. Fars province, where most Qashqa'i live, ranks number 10 $(16.7 \%)$ in stunting and number 13 in wasting $(11.3 \%)$ among children aged $<5$ years compared with the other twenty-seven provinces in Iran (Ministry of Health and Medical Education, 1998). More recently, an empirical study indicated a lack of adequate food for young Qashqa'i children, in part because the children are not fed energy- and protein-rich foods (Salehi et al. 2004).

To address the lack of data on the nutritional status of Qashqa'i school children and how their status compares with other subgroups of children, in the present project we examined the nutritional status of children in a newly settled Qashqa'i sub-tribe and a Persian village about 5 miles apart. Additional objectives were to compare the nutrition-related health status of school children from this sub-tribe and a typical Iranian village. Given that health outcomes are associated with people's lifestyle, collecting baseline data on the Qashqa'i school children at this transitional stage and comparing such data with that from school children of a typical sedentary Iranian village will help us to examine how lifestyle change influences population health over time.

\section{Materials and methods}

Design

The University of Wyoming Institutional Review Board for Protection of Human Subjects approved the study. Data were collected in 
three phases in the native languages (Turkish and Persian). A medical team from Shiraz University of Medical Sciences (including Z. S., a nurse and public health graduate students) supervised/facilitated the medical aspects of the project in the field.

\section{Study population}

The Qashqa'i village consisted of seventy households who formed a village. Prior to settling in the village, they migrated in groups of ten to fifteen households with specific summer and winter quarters scattered over several hundred miles. Each group had a school teacher who accompanied them to both winter and summer quarters. Now several school teachers are assigned to teach in the new village. Modern conveniences for this village including telephone, electricity and running water are under construction. About half of the households have moved into the modern village allowing access not only to telephone services but also to television, etc.

In the past, the diet of the Qashqa'i varied substantially with the seasonal availability of food. During the spring and summer most sheep and goats delivered offspring, making dairy products plentiful. Seasonal fruits such as oranges and apples as well as meat and cheaper grains were also available. During the winter, fruit, meat and dairy consumption was minimal with grains and beans forming dietary staples. Some households in this newly settled village will continue to raise domestic animals, and others will farm. Staples for this newly settled village now include bread, potatoes, aubergine, tomato, rice and occasional meat. These practices, along with paving of the road to the village, should decrease seasonal food variation and influence nutrient intake.

The Persian village population has been settled for over a century. Their diet in the past consisted of products locally available. However, improved roads and better transportation systems are now allowing bread, rice, meat and wheat to be staples. Fruit consumption was uncommon among both populations. With the improved infrastructure in the region, fruit is now available; however, the availability for the Qashqa'i is less. All children in these villages attend elementary schools in their village. One junior high serves both villages. Fewer females attend junior high than males.

\section{Measurements}

Initially, all 137 students attending the elementary schools in the two villages participated in the study. About one-third of children were found to be anaemic. They were given Fe pills for a period of 6 months. Blood Fe level of twenty-five children was measured in December 2002; however, due to a technical error on the measuring device, readings from only eleven subjects were complete and could be included with the results of the forty-one subjects obtained in Phase III. Thus, the number of subjects in Phase III (fifty-two) was calculated. The field project was conducted in three phases.

Phase I. Phase I was conducted in January 2002 before construction of the modern village was completed for the Qashqa'i. Study participants were all 137 children, who attended the elementary schools in the two villages and the middle school serving both villages, on the day of data collection. Heights and weights were obtained using a portable digital scale and portable stadiometer following standard techniques. Blood samples were obtained by venepuncture by medical professionals. Blood samples were analysed in a laboratory at the Shiraz University of Medical Sciences for the following: transferrin saturation, serum $\mathrm{Fe}$, total $\mathrm{Fe}$-binding capacity, serum ferritin, $\mathrm{Hb}$, haematocrit, mean corpuscular volume, mean corpuscular $\mathrm{Hb}$, mean corpuscular $\mathrm{Hb}$ concentration and hepatitis antigen. D. G. conducted parental interviews with the assistance of an Iranian health educator on a sub-sample of forty children. Children who met the cut-offs for anaemia of the Centers for Disease Control and Prevention (1998) were prescribed supplemental Fe by the collaborating physician.

Phase II. Hb was rechecked in December 2002 using a Hemocue (Auratech Inc., Greensboro, NC, USA) on a subsample of twenty-five of the originally anaemic children. A team of researchers travelled to the elementary school sites without previous notification and obtained blood samples from the students present at the time of arrival. At this time, the children were questioned regarding use of $\mathrm{Fe}$ supplements.

Phase III. Heights and weights were re-measured and $\mathrm{Hb}$ was rechecked on a sub-sample of forty-one elementary school children in May 2003. The same protocol as used in Phase II was followed to select students. Students were asked about use of Fe supplements. Thus, two height and weight measurements were available on forty-one children and two $\mathrm{Hb}$ values on fifty-two children. Fourteen children had $\mathrm{Hb}$ checked in both Phase II and Phase III. The value for Phase III was used in analysis to ascertain whether $\mathrm{Hb}$ improved with $\mathrm{Fe}$ supplementation.

\section{Analysis}

Height-for-age Z-score and BMI for age Z-score were calculated using the EPI-Info 2000 Nutristat program (Centers for Disease Control and Prevention, Atlanta, GA, USA) using the CDC 2000 standards. Low height-for-age and low BMI-for-age was defined as Z-score of $<-2$. Since there were only fifteen females aged $12-15$ years, the participants were divided into two age categories for analysis: $<12$ years and $\geq 12$ years of age.

The serum ferritin cut-off of $<12 \mu \mathrm{g} / \mathrm{l}$ (5th percentile) for individuals 6 years of age and older of the Third National Health and Nutrition Examination Survey (NHANES III) was used to identify individuals with low Fe stores (Centers for Disease Control and Prevention, 1998). The Shiraz University of Medical Sciences normal laboratory range for total Fe-binding capacity of 100$400 \mu \mathrm{g} / \mathrm{dl}$, mean corpuscular $\mathrm{Hb}$ concentration of $20-40 \mathrm{~g} / \mathrm{dl}$, mean corpuscular $\mathrm{Hb}$ of $25 \cdot 0-32.0 \mathrm{pg} / \mathrm{cell}$ and serum $\mathrm{Fe}$ of $35-$ $100 \mu \mathrm{g} / \mathrm{dl}$ were used to identify children with abnormal values for these indicators of $\mathrm{Fe}$ status. For children aged 6-11 years, $<80,<82 \mathrm{fl}$ for children aged $12-15$ years and $<85 \mathrm{fl}$ for children over the age of 15 years was used to identify those with abnormal mean corpuscular volume (Centers for Disease Control and Prevention, 1998). The NHANES III cut-offs (5th percentile) of $11.8 \mathrm{~g} / \mathrm{dl}$ for children aged $6-11$ years, $11.9 \mathrm{~g} / \mathrm{dl}$ for female adolescents aged $12-15$ years, $12.6 \mathrm{~g} / \mathrm{dl}$ for male adolescents aged $12-15$ years and $13.6 \mathrm{~g} / \mathrm{dl}$ for male adolescents aged 16-19 years identified individuals with low $\mathrm{Hb}$ values (Centers for Disease Control and Prevention, 1998). Differences in anthropometric and $\mathrm{Fe}$ status indices by age, gender and village were examined using the $\chi^{2}$ statistic.

\section{Results}

Phase I

Forty-two per cent of the participants were from the Qashqa'i village and $58 \%$ were from the Persian village. Participants' 
ages ranged from 7.4 to 19.4 years, with half aged $<12$ years and half aged $\geq 12$ years. Two-thirds of participants were male and one-third female, reflecting the fact that fewer females over 12 years old attend school than males.

The mean BMI-for-age Z-score was - 1·3, with no participant meeting the criterion for overweight (BMI-for-age Z-score $>2$ ). Twenty-nine children $(21 \%)$ met the criterion for wasting (BMIfor-age Z-score $<-2$ ). Twenty per cent of males and $23 \%$ of females, $18 \%$ of Quashqua'i and $24 \%$ of Persian children, and $12 \%$ of children aged $<12$ years and $31 \%$ of children $\geq 12$ years were wasted (Table 1). Ten children $(7.3 \%$; three females and seven males) had BMI-for-age Z-score $<-3$. The percentage of children with low BMIZ-score did not differ significantly by village or gender $(P>0 \cdot 05)$ but did differ by age $(P=0 \cdot 02)$. Seventy-eight or $57 \%$ of children had a height-for-age Z-score meeting the criterion for stunting. Fifty-six per cent of males and $62 \%$ of females, $54 \%$ of Quashqua'i and $59 \%$ of Persian children, and $54 \%$ of children aged $<12$ years and $59 \%$ of children $\geq 12$ years of age were wasted (Table 2). The percentage of low height-for-age Z-scores did not differ by age, gender or village $(P>0.05)$. Thirty-four children ( $25 \%$; ten females and twenty-four males) had a height-for-age Z-score $<-3$.

Results of laboratory tests for Fe status are shown in Table 3 and were available for ninety-nine or $111(72 \%$ or $81 \%)$ children depending on the test. Although only $4 \%$ of those with laboratory results had low ferritin, $71 \%$ had low mean corpuscular volume, $23 \%$ low mean corpuscular $\mathrm{Hb}$ and $19 \%$ low serum Fe. No child had a low total $\mathrm{Fe}$-binding capacity. Hb values were available on 111 or $81 \%$ of participants; $22 \%$ (twenty-four) had low Hb. No significant differences in the prevalence of anaemia by age, gender or village were noted. Of the ninety-five children with a normal serum ferritin, fifty had mean corpuscular volume $<80$ fl. Thirty-two per cent were females and $68 \%$ males; $44 \%$ were $<12$ years old and $66 \%$ were aged $\geq 12$ years older. No child was positive for hepatitis.

In the parental interviews, $100 \%$ of parents reported that their child ate lunch, dinner and a snack, and $91 \%$ reported their child ate breakfast. When asked to classify their child's health status as good, fair or poor, $68 \%$ responded 'good', $25 \%$ 'fair' and $7 \%$ responded 'poor'. When asked to rate their child's food intake with the same categories, $55 \%$ of parents said 'good,' $40 \%$ 'fair' and $4 \%$ said 'poor'. Twenty-three per cent of parents said their child had seen a doctor in the last 12 months.

\section{Phases II and III}

After eliminating implausible values from children who got smaller, two BMI-for-age Z-scores were available for thirty-six children and two height-for-age Z-scores were available for thirty-seven children. Among this sub-sample the initial mean BMI-for-age Z-score was -1.29 and the median was -1.41 . Sixteen months later, the mean BMI-for-age Z-score decreased to -1.48 and the median remained unchanged at -1.42 . The mean difference in BMI-for-age Z-scores was $-0 \cdot 17$, with two scores remaining the same $( \pm 0 \cdot 05)$, ten increasing and twentyfour decreasing. The initial height-for-age $\mathrm{Z}$-score of the subsample was -2.43 and the median was -2.52 . For the second measurement, the mean height-for-age $\mathrm{Z}$-score was -2.20 and the median was $-2 \cdot 32$. The average difference was 0.23 , with five scores remaining the same $( \pm 0 \cdot 05)$, twenty-one increasing and eleven decreasing.

Self-reported compliance for consuming $\mathrm{Fe}$ tablets was still high. Fifty-two children had their $\mathrm{Hb}$ level checked twice. In this sub-sample eleven children $(21 \%)$ were anaemic in Phase I. Of these eleven children, in nine $\mathrm{Hb}$ rose to normal level, in one $\mathrm{Hb}$ improved but was still low, and in one $\mathrm{Hb}$ dropped when rechecked. Additionally, four children whose $\mathrm{Hb}$ was originally normal dropped into the anaemic range when rechecked.

\section{Discussion}

In this study, $22 \%$ of children and adolescents were anaemic. According to a 1993 national study, $11 \%$ of Iranian children between 2 and 14 years of age had Fe-deficiency anaemia (Zohouri \& Rugg-Gunn, 2002). A national survey in 1999 of 15740 children aged 2-14 years found that $14.2 \%$ of females and $15.9 \%$ of males were anaemic (Haghshenass et al. 1972). The prevalence of anaemia in the present population is much greater than in previous studies of Iranian children. Although most of a very small sample of anaemic children responded to Fe therapy, the high prevalence of normal ferritin and low mean corpuscular volume is indicative of anaemia of chronic disease.

Although information on the Fe intake of our population is not available, studies show dietary intake of $\mathrm{Fe}$ among children in urban and rural areas of Fars to be adequate. Zohouri \& Rugg-Gunn (2002) found significant differences in daily $\mathrm{Fe}$ intake between city and provincial districts in the south western province of Fars $(7.73$ and $10.33 \mathrm{mg} / \mathrm{d}$, respectively) but not between gender and season in a study of 4-year-old children. A study of 12-year-old boys in rural Fars province and Shiraz (the major city in Fars province) found that the average $\mathrm{Fe}$ intake was $44 \mathrm{mg} / \mathrm{d}$ (Zohouri \& Rugg-Gunn, 2002). Another study in 1995 of 19-21-year-olds reported average intakes of Fe of $16 \mathrm{mg} / \mathrm{d}$ for females and $20 \mathrm{mg} / \mathrm{d}$ for males (Zohouri \& Rugg-Gunn, 2002).

However, differences in Fe absorption from different foods make total Fe intake a poor indicator of dietary adequacy. A 1972 survey

Table 1. Prevalence of wasting in 137 school children in rural Fars province in Iran by gender, village and age

(Number of children in each category)

\begin{tabular}{lrcccccc}
\hline & Total & Female & Male & Persian & Quashqua'i & $<12$ years & $\geq 12$ years \\
\hline Wasted $^{*}$ & 29 & 11 & 18 & 19 & 10 & 8 & 21 \\
Normal† & 108 & 36 & 72 & 61 & 47 & 58 & 56 \\
Total & 137 & 47 & 90 & 80 & 57 & 66 & 67 \\
\hline
\end{tabular}

${ }^{*}$ BMI-for-age Z-score $<-2$.

†BMI-for-age Z-score $>-2$ and $<2$. 
Table 2. Prevalence of stunting in 137 school children in rural Fars province in Iran by gender, village and age

(Number of children in each category)

\begin{tabular}{lccccccc}
\hline & Total & Female & Male & Persian & Quashqa'i & $<12$ years & $\geq 12$ years \\
\hline Stunted* $^{*}$ & 78 & 29 & 49 & 47 & 31 & 36 & 42 \\
Normal† & 59 & 18 & 41 & 33 & 26 & 30 & 29 \\
Total & 137 & 47 & 88 & 80 & 57 & 66 & 71
\end{tabular}

${ }^{*}$ Height-for-age Z-score $<-2$

† Height-for-age $Z$-score $>-2$ and $<2$

in rural areas of southern Iran noted that $30 \%$ of children were anaemic despite an intake of Fe greater than recommended (Haghshenass et al. 1972). A study of dietary sources of $\mathrm{Fe}$ of 103 children aged 4 years in Shiraz and a provincial town in Fars province reported that $71 \%$ of $\mathrm{Fe}$ intake came from plant sources while $23 \%$ came from animal sources, with almost half the total $\mathrm{Fe}$ intake coming from bread. The contribution of plant sources to total $\mathrm{Fe}$ intake was significantly greater for the provincial district than in the city $(75 \% v .60 \%)$. Meat is recognized as an excellent source of bioavailable Fe. However, only $7 \%$ of dietary Fe intake in the provincial children and $16 \%$ in the city children came from meat. This compares with $29 \%$ in Swedish children and $17 \%$ in British children (Zohouri \& Rugg-Gunn, 2002).

Phytates in cereals and legumes, and polyphenols in tea and coffee, inhibit $\mathrm{Fe}$ absorption while vitamin $\mathrm{C}$ in fruits and vegetables enhances absorption of $\mathrm{Fe}$ (World Health Organization Regional Office for the Eastern Mediterranean, 2001; Dickey, 2002). In the previously mentioned study, phytate-rich bread was an important source of Fe supplying $27 \% \mathrm{Fe}$ in the city and $51 \%$ in the provincial district (Zohouri \& Rugg-Gunn, 2002). Tea is a popular drink in Iran even among children, especially in rural areas. The 4-year-old children in Shiraz drank the equivalent of one ordinary Iranian tea cup while the provincial children consumed about two to four cups daily. It is recommended that tea be given $1-2 \mathrm{~h}$ after meals to prevent inhibition of Fe absorption.

Factors in addition to dietary habits possibly contributing to the anaemia noted in these children include parasitic and infectious disease, and gastrointestinal bleeding (Zohouri \& Rugg-Gunn, 2002). Fifty children had normal serum ferritin and low mean corpuscular volume values indicative of anaemia of chronic disease. In pre-school children in Tanzania, a low-dose Fe supplement improved $\mathrm{Fe}$ status and appetite but did not improve anaemia. Quarterly anthelmintic treatment improved not only appetite and Fe status but also growth (Stoltzfus et al. 2003).

One possible source of infection is the bacterium Helicobacter pylori. H. pylori infection is present in $80 \%$ of the population in developing countries; the prevalence of infection among individuals aged 6-20 years was reported as $47.5 \%$ in one province and $30.6 \%$ in another province in Iran (Mikaeli et al. 2003). Infection with $H$. pylori has been associated with several micronutrient deficiencies including Fe (Annibale et al. 2002; Dickey, 2002; Yakoob et al. 2003). H. pylori has been associated with $\mathrm{Fe}-$ deficiency anaemia in 6-12-year-old Korean children (Seo et al. 2002), Korean female adolescents but not males (Choe et al. 2003), Alaskan natives (Petersen et al. 1996; Yip et al. 1997; Parkinson et al. 2000), Indian adults (Pavithran et al. 2003) and French adults (Nahon et al. 2003). It has been speculated (Choe et al. 2003) that a relationship between $H$. pylori and $\mathrm{Fe}$ deficiency anaemia is found in females but not males due to their marginal Fe status. H. pylori infection should be considered a cause of $\mathrm{Fe}$ deficiency refractory to $\mathrm{Fe}$ supplementation (Choe et al. 2003; Pavithran et al. 2003).

The prevalence of stunting was very high and increased throughout the 1.5 years of the study. Stunting was higher initially among children aged $\geq 12$ years, indicating possible delayed puberty. $\mathrm{Zn}$ deficiency may be contributing to the high prevalence of stunting. Zn deficiency was identified as a cause of stunting and delayed development in the Middle East in the 1970s (Sandstead, 1991). According to a review of community-based, randomized, placebo-controlled micronutrient supplementation trials even mild or moderate $\mathrm{Zn}$ deficiency may affect growth (Rivera et al. 2003). Zn deficiency occurs in populations whose diets are low in rich sources of $\mathrm{Zn}$ such as red meat and high in whole-grain cereals rich in fibre and phytate, which decrease $\mathrm{Zn}$ absorption. Additionally tannins in tea can decrease Zn absorption (Sandstead, 1998; PDRHealth, 2004).

$\mathrm{Zn}$ deficiency has been reported in children and adolescents from Egypt, Iran, Turkey, China, Yugoslavia and the USA (Sandstead, 1991). A 1997 study of 881 adolescents in Tehran reported that almost one-third showed biochemical signs of $\mathrm{Zn}$ deficiency and $50 \%$ consumed less than $50 \%$ of their $\mathrm{Zn}$ requirement according to $24 \mathrm{~h}$ diet recalls (Mahmoodi \& Kimiagar, 2001). The addition of animal foods with micronutrient supplements or other supplemental foods or the addition of skimmed

Table 3. Results of tests of iron status in 137 Iranian school children

(Number of children in each category and percentage in parentheses)

\begin{tabular}{lcccr}
\hline Test & Low & Normal & High & Missing \\
\hline Serum ferritin & $4(2 \cdot 9)$ & $95(69 \cdot 3)$ & 0 & $38(27 \cdot 7)$ \\
Total Fe-binding capacity & 0 & $74(54 \cdot 0)$ & $25(18 \cdot 2)$ & $38(27 \cdot 7)$ \\
Mean corpuscular volume & $79(57 \cdot 7)$ & $32(23 \cdot 3)$ & 0 & $26(19 \cdot 0)$ \\
Mean corpuscular Hb concentration & 0 & $111(81 \cdot 0)$ & 0 & $26(19 \cdot 0)$ \\
Mean corpuscular Hb & $25(18 \cdot 2)$ & $86(62 \cdot 8)$ & 0 & $26(19 \cdot 0)$ \\
Serum Fe & $19(13.9)$ & $67(48 \cdot 9)$ & $13(9 \cdot 5)$ & $38(27 \cdot 7)$ \\
$\mathrm{Hb}$ & $24(17 \cdot 5)$ & $84(61.3)$ & $3(2 \cdot 2)$ & $26(19 \cdot 0)$ \\
\hline
\end{tabular}


milk powder alone enhances growth (Rivera et al. 2003). According to the Nutrition Collaborative Research Support Programme, diets of primarily vegetarian children in rural Egypt, Kenya and Mexico were low in vitamin $\mathrm{A}$, vitamin $\mathrm{B}_{12}$, riboflavin, $\mathrm{Ca}, \mathrm{Fe}$ and $\mathrm{Zn}$ leading to anaemia, poor growth, impaired cognitive performance and poor growth (Murphy \& Allen, 2003).

Other nutrient inadequacies may be present, as there are no good data on the nutrient intake of children in the present study. Meal and snack consumption was regular among this sample. Breakfast was the meal most often skipped, although only $9 \%$ of mothers reported their child did not eat breakfast. This compares with $15 \%$ of school children in a large study in Saudia Arabia (Abalkhail \& Shawky, 2002).

It is known that the study children and their families lead a subsistence lifestyle and there is seasonal variety in their food intake. The extent to which energy inadequacy, other micronutrient deficiencies in addition to $\mathrm{Fe}$ and $\mathrm{Zn}$, or the presence of parasites could be contributing to poor growth has not yet been investigated. In Kenyan school children, multiple nutrient deficiencies $\left(\mathrm{Ca}, \mathrm{Zn}, \mathrm{Fe}\right.$, riboflavin, vitamin $\mathrm{A}$ and vitamin $\left.\mathrm{B}_{12}\right)$ attributed to a diet low in animal products and high in fibre and phytates have been linked to stunting, poor development and rickets (Bwibo \& Neumann, 2003; Neumann et al. 2003). Dietary supplementation with meat or milk enhanced gain in weight and lean body mass in these children and improved cognitive performance (Grillenberger et al. 2003; Whaley et al. 2003). In 30-90month-old rural Malawian children, supplementation of their maize-based diet with more animal foods and decreasing phytic acid increased energy, protein, $\mathrm{Ca}$, available $\mathrm{Zn}$, haem $\mathrm{Fe}$ and vitamin $\mathrm{B}_{12}$. The supplementation also increased mid-arm circumference and arm muscle area and decreased anaemia and common infections (Gibson et al. 2003).

\section{Conclusion}

Increasing access to animal foods and fruits and vegetables is one suggestion for improving the nutritional status of the present study population. Animal foods are high in $\mathrm{Fe}$ and $\mathrm{Zn}$, and the vitamin $\mathrm{C}$ in fruits and vegetables enhances $\mathrm{Fe}$ absorption. In fact, this is one of the four parts of the WHO's Comprehensive Regional Strategy for the Eastern Mediterranean for combating Fe deficiency and anaemia. The other parts are: supplementation with Fe tablets; public health activities, such as the control of parasitic infestations and family planning; the fortification of staple food with Fe (World Health Organization Regional Office for the Eastern Mediterranean, 2001). Further investigation into the cause of stunting, wasting and anaemia is recommended in this unique population to improve its health and nutritional status. This should include a comprehensive assessment of dietary intake and tests for $\mathrm{H}$. pylori and other infectious agents. The inprogress phases of the present project are investigating these unknowns.

\section{References}

Abalkhail B \& Shawky S (2002) Prevalence daily breakfast intake, iron deficiency anemia and awareness of being anaemic among Saudi school students. Int J Food Sci Nutr 53, 519-528.

American Academy of Pediatrics Committee on Nutrition (1998) Cholesterol in childhood. Pediatrics 101, 141-147.
Annibale B, Capurso G \& Delle Fave G (2002) Consequences of Helicobacter pylori infection on the absorption of micronutrients. Dig Liver Dis 34, Suppl. 2, S72-S77.

Azizi F, Allahverdian S, Mirmiran P, Rahmani M \& Homammadi F (2001a) Dietary factors and body mass index in a group of Iranian adolescents: Tehran lipid and glucose study-2. Int J Vitam Nutr Res 71, $123-127$.

Azizi F, Rahmani M, Madjid M, Allahverdian S, Ghanbili J, Ghanbarian A \& Hajipour R (2001b) Serum lipid levels in an Iranian population of children and adolescents: Tehran lipid and glucose study. Eur J Epidemiol 17, 281-288.

Bwibo NO \& Neumann CG (2003) The need for animal source foods by Kenyan children. J Nutr 133, Suppl., 3936S-3940S.

Centers for Disease Control and Prevention (1998) Recommendations to prevent and control iron deficiency in the United States. MMWR 47, 1-28.

Choe YH, Kim SK \& Hong YC (2003) The relationship between Helicobacter pylori infection and iron deficiency: sero-prevalence study in 937 pubescent children. Arch Dis Child 88, 178.

CIA (2003) Iran. The World Factbook. http://www.cia.gov/cia/publications/ factbook/geos/ir.html

Dickey W (2002) Iron deficiency, gastric atrophy and Helicobactor pylori. Dig Liver Dis 34, 313-315.

Gibson RS, Yeudali F, Drost N, Mtitimuni BM \& Cullinan TR (2003) Experience of a community based dietary intervention to enhance micronutrient adequacy of diets in animal source foods and high in phytates: a case study in rural Malawian children. J Nutr 133, Suppl., 3992S-3999S.

Grillenberger M, Neumann CG, Murphy SP, Bwibo NO, van't Veer P, Hautvast JG \& West CE (2003) Food supplements have a positive impact weight gain and the addition of animal source foods increases lean body mass of Kenyan schoolchildren. J Nutr 133, Suppl., 3957S-3964S.

Haghshenass M, Mahloudji M, Reinhold JG \& Mohammad N (1972) Irondeficiency anaemia in an Iranian population associated with high intakes of iron. Am J Clin Nutr 25, 1143-1146.

Kadivar MR, Yarmohammadi H, Mirahmadizadeh AR, Vakili M \& Karimi M (2003) Prevalence of iron deficiency anemia in 6 months to 5 years old children in Fars, Southern Iran. Med Sci Monit 9, CR100-CR104.

Karimi M, Kadivar R \& Yarmohammadi H (2002) Assessment of the prevalence of iron deficiency anemia by serum ferritin in pregnant women in southern Iran. Med Sci Monit 8, CR488-CR492.

Keshavarz H \& Sarraf Z (1997) Qashqa'i tribeswomen and their health. Rev Epidemiol Sante Publique 45, 279-285.

Mahmoodi MR \& Kimiagar SM (2001) Prevalence of zinc deficiency in junior high school students of Tehran City. Biol Trace Elem Res 81, 93-103.

Mikaeli J, Malekzadeh R, Ziad Alizadeh B, Nasseri S, Mogaddam, Valizadeh M, Khoncheh R \& Massarrat S (2003) Prevalence of Helicobacter pylori in two Iranian provinces with high and low incidence of gastric carcinoma. Tehran, Iran: Digestive Diseases Research Center, Tehran University of Medical Sciences

Ministry of Health and Medical Education (1998) The Nutritional Status of Children October-November. Tehran: Ministry of Health and Medical Education.

Murphy SP \& Allen LH (2003) Nutritional importance of animal source foods. J Nutr 133, Suppl., 3932S-3935S.

Nahon S, Lahmek P, Massard J, Lesgourgues B, Mariaud de Serre N, Traissac L, Bodiguel V, Adotti F \& Delas N (2003) Helicobacter pylori-associated chronic gastritis and unexplained iron deficiency anemia: a reliable association? Helicobacter 8, 573-577.

Neumann CG, Bwibo NO, Murphy SP, Sigman M, Whaley S, Allen LH, Guthrie D, Weiss RE \& Demment MW (2003) Animal source foods improve dietary quality, micronutrient status, growth and cognitive function in Kenyan school children: background, study design and baseline findings. J Nutr 133, Suppl., 3941S-3949S.

Parkinson AJ, Gold BD, Bulkow L, Wainwright RB, Swaminathan B, Khanna B, Petersen KM \& Fitzgerald MA (2000) High prevalence of 
Helicobacter pylori in the Alaska native population and association with low serum ferritin levels in young adults. Clin Diagn Lab Immunol 7, 885-888.

Pavithran K, Arjun R, Aruna R \& Thomas M (2003) Refractory iron deficiency anemia - is Helicobacter pylori the culprit? MedGenMed 5, 32.

PDRhealth (2004) Zinc. http://pdrhealth.com/drug_info/nmdrugprofiles/ nutsupdrugs/zin_0281.shtml.

Petersen KM, Parkinson AJ, Nobmann ED, Bulkow L, Yip R \& Mokdad A (1996) Iron deficiency anemia among Alaska natives may be due to fecal loss rather than inadequate intake. J Nutr 126, 2774-2783.

Rivera JA, Hotz C, Gonzalez-Cossio T, Neufeld L \& Garcia-Guerra A (2003) The effect of micronutrient deficiencies on child growth: a review of results from community-based supplementation trials. $J$ Nutr 133, Suppl., 4010S-4020S.

Salehi M, Kimiagar SM, Shahbazi M, Mehrabi Y \& Kolahi AA (2004) Assessing the impact of nutrition education on growth indices of Iranian nomadic children: an application of a modified beliefs, attitudes, subjective-norms and enabling-factors model. $\mathrm{Br} J$ Nutr $\mathbf{9 1}$, $779-787$.

Sandstead HH (1991) Zinc deficiency. A public health problem? Am J Dis Child 145, 853-859.

Sandstead HH (1998) Zinc deficiency and development. http://www.iza.c/ omzhe_org/Articles/Art-02.htm
Seo JK, Ko JS \& Choi KD (2002) Serum ferritin and Helicobacter pylori infection in children: a sero-epidemiologic study in Korea. J Gastroenterol Hepatol 17, 754-757.

Stoltzfus RJ, Chway HM, Montresor A, Tielsch JM, Jape JK, Albonico M \& Savioli L (2003) Low dose daily iron supplementation improves iron status and appetite but not anemia, whereas quarterly anthelminthic treatment improves growth, appetite and anemia in Zanzibari preschool children. J Nutr 134, 348-356.

Whaley SE, Sigman M, Neumann C, Bwibo N, Guthrie D, Weiss RE, Alber S \& Murphy SP (2003) The impact of dietary intervention on the cognitive development of Kenyan school children. J Nutr 133, Suppl., 3965S-3971S.

World Health Organization Regional Office for the Eastern Mediterranean (2001) Half of children and women in eastern Mediterranean region are anaemic. http://www.emro.who.int/NFS/Flour FortificationPressRelease1306.htm

Yakoob J, Jafri W \& Abid S (2003) Helicobacter pylori infection and micronutrient deficiencies. World J Gastroenterol 9, 2137-2139.

Yip R, Limburg PJ, Ahlquist DA, et al. (1997) Pervasive occult gastrointestinal bleeding in an Alaska native population with prevalent iron deficiency. Role of Helicobacter pylori gastritis. JAMA 277, 1135-1139.

Zohouri FV \& Rugg-Gunn AJ (2002) Sources of dietary iron in urban and provincial 4-year-old children in Iran. Asia Pac J Clin Nutr 11, 128-132. 